\title{
Rules of Engagement in Minimal Blood Loss Palatoplasty Using Saline Hydro Dissection: A Useful Learning Curve for Younger Cleft Surgeons in Manoeuvring Areas of Static Resistance due to Tight Tissue Planes
}

\author{
Bona Lotha ${ }^{1 *}$ and Zeinalddin $\mathbf{M}^{2}$ \\ ${ }^{1}$ Craniofacial Cleft Surgeon, Yemen Global Smiles, Sanaa, Yemen \\ ${ }^{2}$ Craniofacial Orthodontist Mohammad Orthodontic Center - Senior Lecturer Oman \\ Dental College, Muscat, Sultanate of Oman \\ *Corresponding Author: Bona Lotha, Craniofacial Cleft Surgeon, Yemen Global \\ Smiles, Sanaa, Yemen.
}

Received: September 22, 2020

Published: October 14, 2020

(C) All rights are reserved by Bona Lotha and

Zeinalddin M.

\begin{abstract}
Minimal blood loss in palatoplasty can be achieved with adrenaline saline hydro dissection, and a good knowledge of key anatomical structures as well as the stubborn areas of static resistance, where dissection is difficult because of fixed tissue planes. With the advent of minimal incision palatoplasty, button-hole and medial-only incision procedures, the amount of blood loss is significantly reduced in most palate operations. The two-stage palate repair also leads to less blood loss and is a popular concept among cleft groups worldwide following the initial promotion by Swedish cleft groups at Gothenburg. The learning curve is reasonable and techniques can be added, as one gains more experience with cleft palate surgeries.
\end{abstract}

Keywords: Minimal Blood Loss Palatoplasty; Cleft Training; Minimal Incision Palate Repair; Saline Hydro Dissection

\section{Introduction}

Minimal incision palatoplasty is an attractive concept, especially for younger cleft surgeons because of the easy learning curve and very little blood loss. The abstract on minimal blood loss palatoplasty was accepted by the scientific committee as a short oral presentation for the $5^{\text {th }}$ European Plastic Surgery Research Council, 22 - 25 August 2013 in Hamburg, Germany [1].

In this technique, we use a dilute solution of adrenaline in saline for easy dissection of the cleft palate. The recommended maximum dose of epinephrine in combination with lidocaine is 1 to 10 microgram/kg and some have used the upper limit at 30-minute intervals without any side effects; epinephrine without lidocaine admixture can be safely used in the pediatric population [2].

Our preference is to use a dilute solution of 1:500,000 saline adrenaline hydro dissection in all our cases; we have not experienced tachycardia or arrhythmia. Saline hydro dissection with
1:500,000 adrenaline in saline has been advocated to reduce bleeding in older patients. This idea was shared by the craniofacial surgeon with the US International Taskforce on palatoplasty for latecomers at Cleft 2013 when he was invited by Prof Jeffrey Marsh, (Chairman, Cleft 2013) to initiate the online discussions for palatoplasty in latecomers [3].

Minimalist palatoplasty has become a popular procedure, especially in low and middle-income smile missions because it has the advantage of being a relatively easy procedure without any post-operative hypoxemia due to lengthy surgeries in children. As a result, patients rarely face postoperative hypoxemia for long, and there has been no need for re-intubation [4].

The commonly performed procedures with adrenaline saline hydro dissection, to minimize blood loss includes buttonhole incisions, and levator retro positioning along with $2 / 3$ uvular retro positioning [5].

Citation: Bona Lotha and Zeinalddin M. "Rules of Engagement in Minimal Blood Loss Palatoplasty Using Saline Hydro Dissection: A Useful Learning Curve for Younger Cleft Surgeons in Manoeuvring Areas of Static Resistance due to Tight Tissue Planes”. Acta Scientific Medical Sciences 4.11 (2020): $36-42$. 
The technique is suitable for Veau 1 and smaller Veau 2 cleft palate defects. This is modified for larger clefts of Veau 2 - 4, where we sometimes use a two-staged procedure, especially in humanitarian missions. The second stage which is done after 12 to 16 months, includes unilateral neurovascular bundle release and hemi hinge palatoplasty. This protocol may be necessary for wider cleft palates in latecomers. Most speaking individuals with unrepaired cleft palates are found in developing nations, where cleft surgeons work in less than favorable conditions.

The technique of adrenaline saline hydro dissection was used for stage one palatoplasty for smaller defects which could be closed primarily using either medial only incisions or buttonhole near the hook of Hamulus [6] (Veau 1 and smaller Veau 2), for primary closure of Veau 2 using Langenbeck variants, for second stage palatoplasty using a hemi hinge flap.

In older children (above 3 - 5 years of age and adults) because of the fear of blood loss, we followed the 1944 Schweckendiek 2 stage protocol popularized by Gothenburg, Sweden. In the Swedish study, 55 patients had surgical procedures at Sahlgrenska University Hospital, Gothenburg, Sweden. They found that stage one soft palate repair was beneficial for speech in the long term and improved even before hard palate repair [7].

Our first preference would always be a single-stage palatoplasty using levator and uvula retro positioning, a modified double opposing z plasty along with Langenbeck variants ranging from the minimal incision, buttonhole, or lateral incision two flap procedure in larger palates. The two-stage surgery is also considered, especially in humanitarian missions where adequate facilities may not be available. A recent study by a group in Japan suggested that twostage palatoplasty is advantageous for jaw development. They also found that after the first stage, the palate narrows spontaneously [8].

Rohrich., et al. suggested an earlier timing for soft palate closure at 3 to 6 months, followed by hard palate at 15 to 18 months [9].

We prefer to perform the one stage palatoplasty between 12 to 16 months of age. In a two-stage procedure, we perform the first stage at 6 - 7 months and hard palate about one and a half years later. During levator retro positioning, the muscle is oriented in an anatomically correct, horizontal position according to Krien's analysis where he noted that the cleft muscle was oriented sagit- tally and suggested the release of abnormal insertions to a more horizontal position [10].

Despite the lack of consensus between cleft palate surgeons, the intra velar veloplasty and Furlows, with some modifications by different surgeons, have remained the most useful surgeries for speech with good outcomes. Furlow [11] and IVVP [12] with Langenbeck variants, without pushback procedures, have arguably established themselves as near true constants in palatoplasty solutions. Both these procedures have low morbidity rates, improved speech scores, and low re-operation rates. In IVVP [13] we normally follow a more conservative route with less muscle and tissue dissection, focusing more on the levator repositioning. Success outcomes are generally good, and these procedures present an advantage over potentially airway obstructive procedures. The IVVP with its low fistula rate, user-friendly variations, and reasonable learning curve, appears to be a good choice. It is also more anatomically correct in terms of levator repositioning. One might argue that the procedure as a secondary solution may be a belated pointer to IVVP along with a modified double opposing z plasty, as a preferred primary procedure [14].

\section{Materials and Methods}

The samples we have chosen for this study from our humanitarian smile mission experience show different examples of how minimal blood loss palatoplasty was performed in our missions over the years, (courtesy Yemen Global Smiles). Most of the patients were latecomers in palatoplasty (after 3 years of age). For this, we have chosen a relatively bloodless method using 1: 500,000 saline adrenaline hydro dissection by mixing $1 \mathrm{mg}$ adrenaline in $500 \mathrm{ml}$ saline. The distension allows for an easy approximation of flaps (Figure $1 \mathrm{a}$ and $1 \mathrm{~b}$ ).

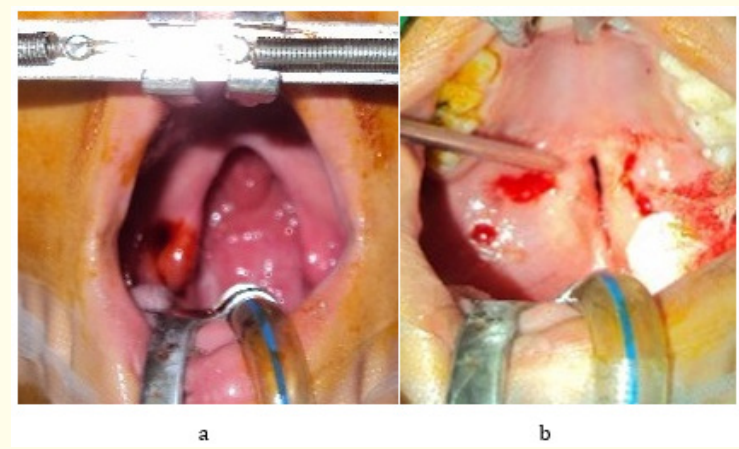

Figure 1:Example of saline hydro dissection with medial-only incision for smaller Veau 2 cleft palate.

Citation: Bona Lotha and Zeinalddin M. "Rules of Engagement in Minimal Blood Loss Palatoplasty Using Saline Hydro Dissection: A Useful Learning Curve for Younger Cleft Surgeons in Manoeuvring Areas of Static Resistance due to Tight Tissue Planes". Acta Scientific Medical Sciences 4.11 (2020): $36-42$. 
Using fine angled Potts scissors, the levators are dissected from their insertion on the palatal aponeurosis/bony hard palate and repositioned in a transverse position from their abnormal sagittal orientation (Figure $2 \mathrm{a}$ and $2 \mathrm{~b}$ ); the uvular is pared, $2 / 3$ retro positioned.

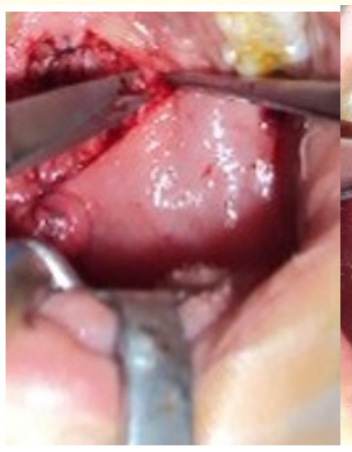

a

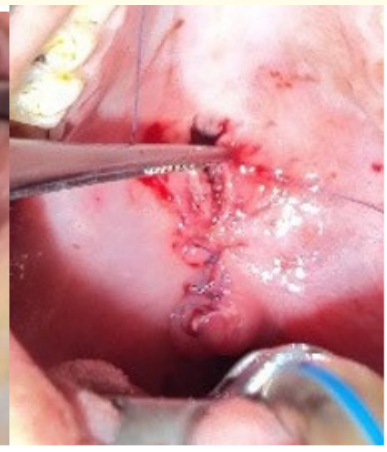

$\mathrm{b}$
Figure 2:a. Dissection of levator muscle with angled scissors b. Final closure without tension.

A small button-hole incision is made over the hamulus to fracture the bone, incise the tensor and medialize the muscles. The closure with this procedure is easy and straightforward.

Linear closure of the soft palate is no longer advocated because it can cause shortening. Instead, a double opposing z plasty is added anteriorly and posteriorly to lengthen the palate. Surgeons have different preferences, and ours is to follow this simple procedure in most cases. For the deceptively simple sub mucus cleft palate, (smcp) our approach would be a modified Furlows.

Other examples: (sample pictures, courtesy Yemen Global Smiles).

The complete (larger Veau 2, to 4) palate is closed in 2 stagesstage one includes soft palate closure with levator retro positioning; the stage 2 minimal incision palatoplasty is done after a year or year and a half. Stage 2 hard palate closure is often easier because of the spontaneous narrowing of the palate after stage one. A hemi flap, hinge palate repair is done.

In the second stage of palatoplasty, we have identified some areas of Resistance Statique (RS), (static resistance, Figure 17) and suggest ways to solve the problems. Static resistance areas are found in the following zones (Table 1).

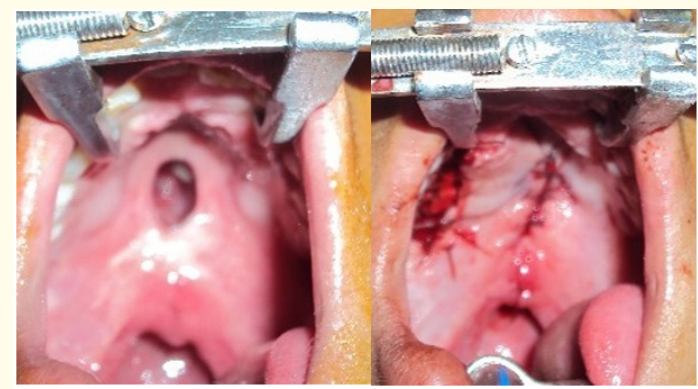

Figure 3: $2^{\text {nd }}$ stage hard palate closure using a hemi palate hinged flap and surgical for the raw area.

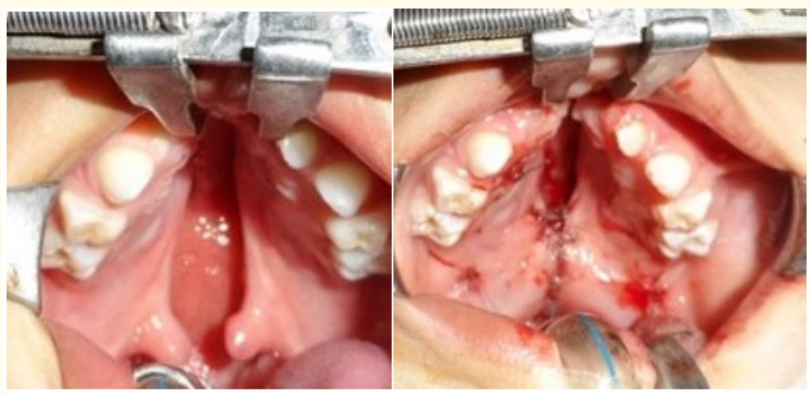

Figure 4: Stage one soft palate closure and levator retro positioning in the Gothenburg protocol for Veau 2.

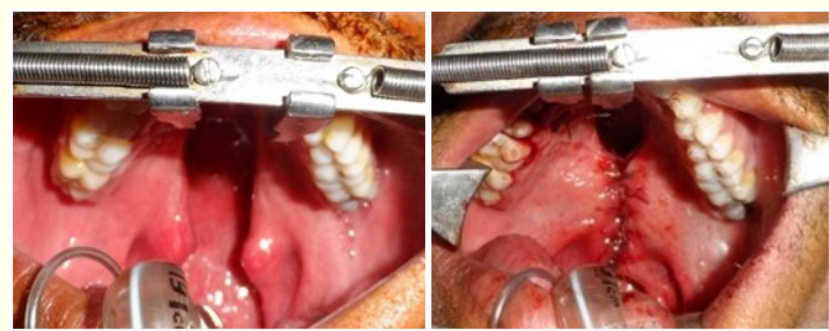

Figure 5: Stage one soft palate closure and levator retro positioning in Gothenburg protocol for Veau 2.

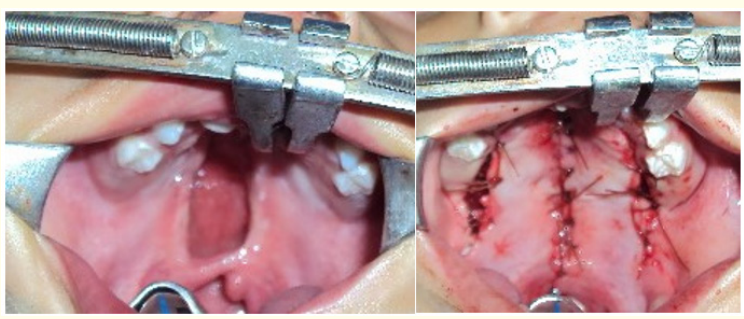

Figure 6: Langenbeck variant in Veau 2. 


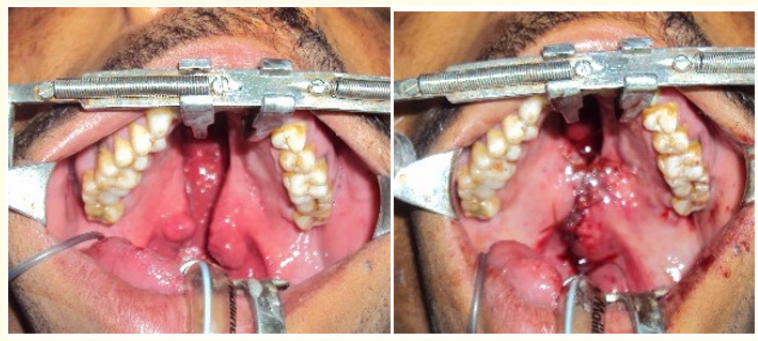

Figure 7: Veau 2, stage one soft palate and levator retro positioning in adult cleft palate.

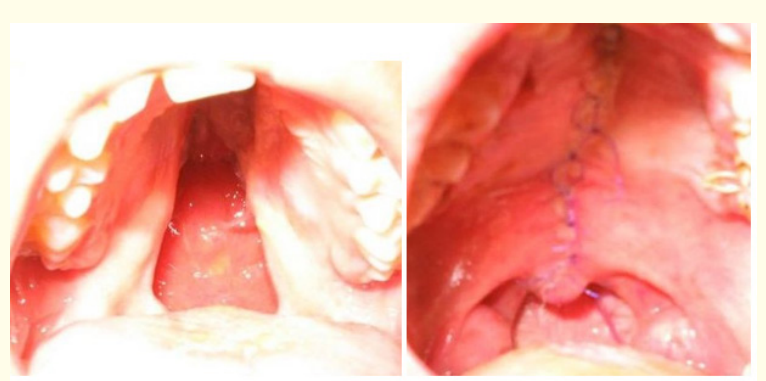

Figure 8: Two flap Langenbeck variant with minimal release done for adult, complete bilateral cleft palate.
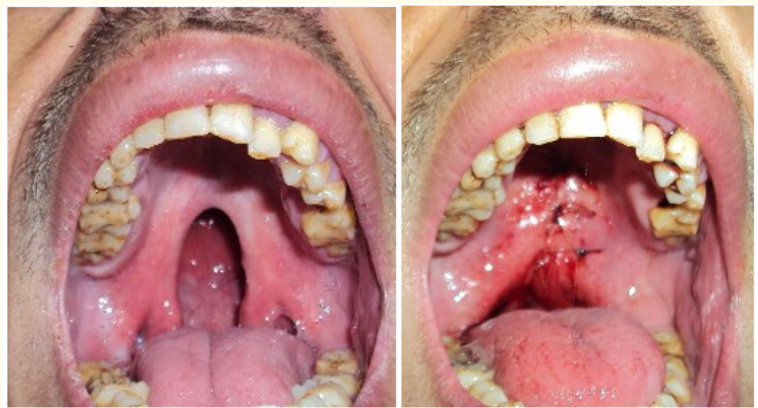

Figure 9: Veau 2 cleft palate: levator retro positioning and stage one soft palate closure in an adult cleft palate.

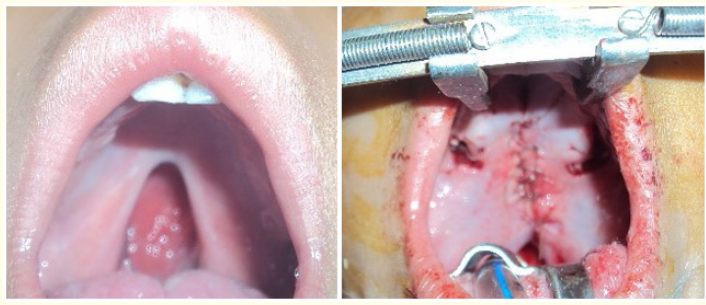

Figure 10: Veau 2, button hole saline hydro dissection-variant surgery.
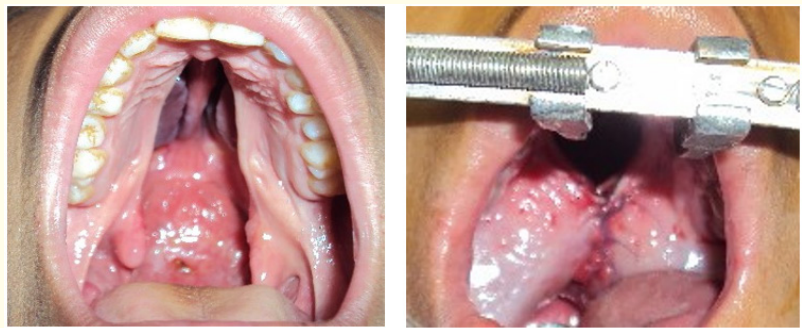

Figure 11: Complete bilateral cleft palate adult, stage one palatoplasty.

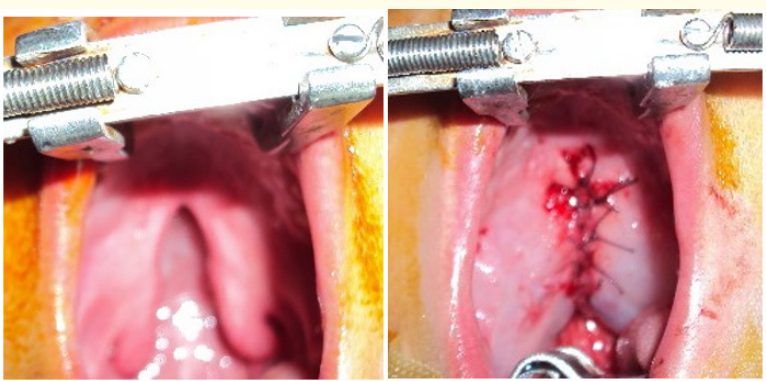

Figure 12: Veau 2 palate, stage one medial-only incision palatoplasty with levator retro positioning.

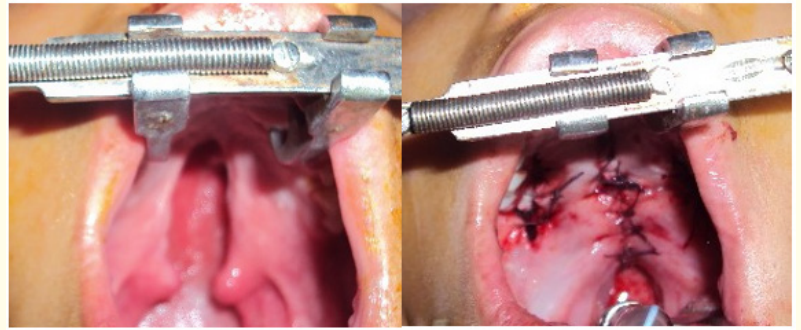

Figure 13: Veau 2: levator retro positioning and hemi- palate hinge flap.

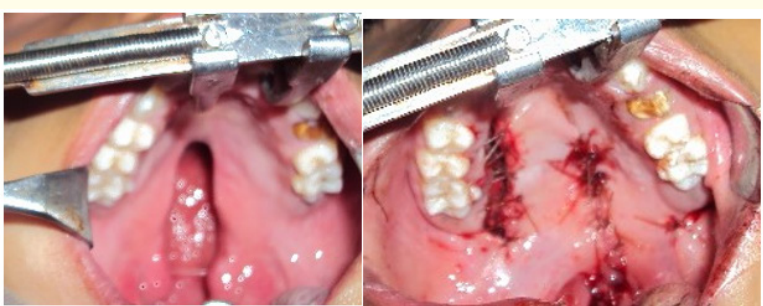

Figure 14: Veau 2, levator retro positioning and hemi-palate hinge flap. 


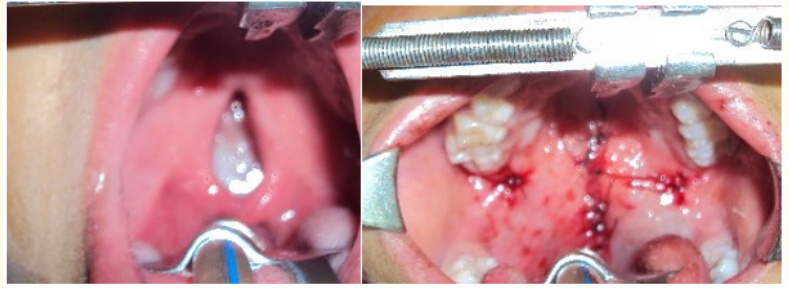

Figure 15: Button-hole palatoplasty with hydro dissection for Veau 2.

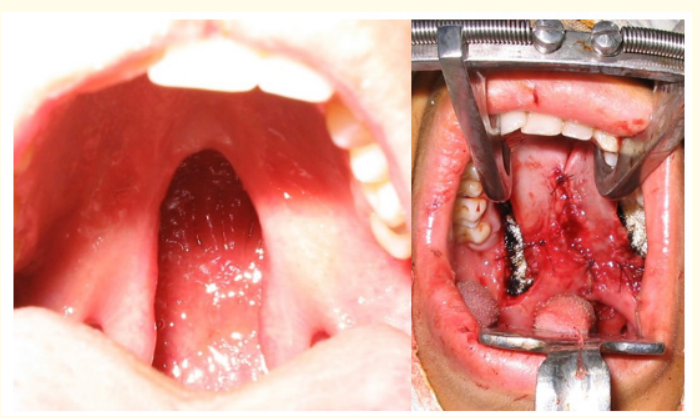

Figure 16: The Langenbeck variant flap for Veau 2 palate repair.

\begin{tabular}{|c|c|c|c|}
\hline $\begin{array}{l}\text { Zone } 1 \text { RS: Near poste- } \\
\text { rior spine area }\end{array}$ & Zone 2 RS: Neurovascular bundle & $\begin{array}{l}\text { Zone } 3 \text { RS: The medial part of } \\
\text { hard palate flap with nasal mu- } \\
\text { cosa }\end{array}$ & $\begin{array}{l}\text { Zone } 4 \text { RS: Palatal aponeu- } \\
\text { rosis }\end{array}$ \\
\hline $\begin{array}{l}\text { The muscle fibers and } \\
\text { mucosa are gently teased } \\
\text { away from the bone with } \\
\text { a sharp fine dissector } \\
\text { (dental) or blade to re- } \\
\text { lease the tense adhesions } \\
\text { around. }\end{array}$ & $\begin{array}{l}\text { The bundle is about } 5 \text { millimeters from } \\
\text { the margin of the arch and can easily be } \\
\text { injured since it is tightly held down by } \\
\text { periosteum. The bundle is approached } \\
\text { from above after raising the mucoperios- } \\
\text { teal flap along the mid rugae. The tissue } \\
\text { is less vascular and looser here. Saline } \\
\text { hydro dissection helps. }\end{array}$ & $\begin{array}{l}\text { The nasal mucosa is tightly ad- } \\
\text { herent and can be gently re- } \\
\text { leased using by a fine dissector in } \\
\text { a horizontal direction, instead of } \\
\text { downwards, which tears the frag- } \\
\text { ile mucosa. }\end{array}$ & $\begin{array}{l}\text { The tight junction along the } \\
\text { posteroinferior aspect of } \\
\text { the palatal bone can restrict } \\
\text { the mobility of the flaps. }\end{array}$ \\
\hline $\begin{array}{l}\text { Avoid rough handling in } \\
\text { this area to prevent holes } \\
\text { in the mucosa }\end{array}$ & $\begin{array}{l}\text { The cone of periosteum is incised with a } \\
\text { blade around the bundle to release the } \\
\text { vessel and nerve. Using a } 1 \mathrm{~mm} \text { guarded } \\
\text { osteotome, a posteromedial palatal ostec- } \\
\text { tomy may be done in very wide palates. }\end{array}$ & $\begin{array}{l}\text { After the mucoperiosteal flap is } \\
\text { elevated from lateral to medial, } \\
\text { a cuff of medial oral mucosa is } \\
\text { taken to give us more tissue on } \\
\text { the nasal side. }\end{array}$ & $\begin{array}{l}\text { After hamulus fracture to } \\
\text { medialize the muscles, and } \\
\text { gentle dissection of the lev- } \\
\text { ators, the aponeurosis is in- } \\
\text { cised parallel to the inferior } \\
\text { edge of palatal bone with a } \\
\text { number } 15 \text { blade }\end{array}$ \\
\hline $\begin{array}{l}\text { saline hydro dissection } \\
\text { helps here }\end{array}$ & $\begin{array}{l}\text { An occasional stalactite of bone may need } \\
\text { to be removed medial to the vessel and } \\
\text { nerve. }\end{array}$ & $\begin{array}{l}\text { One can avoid tearing the nasal } \\
\text { mucosa by staying on the bone, } \\
\text { horizontally at all times }\end{array}$ & $\begin{array}{l}\text { some divide the tensor ten- } \\
\text { don as well }\end{array}$ \\
\hline
\end{tabular}

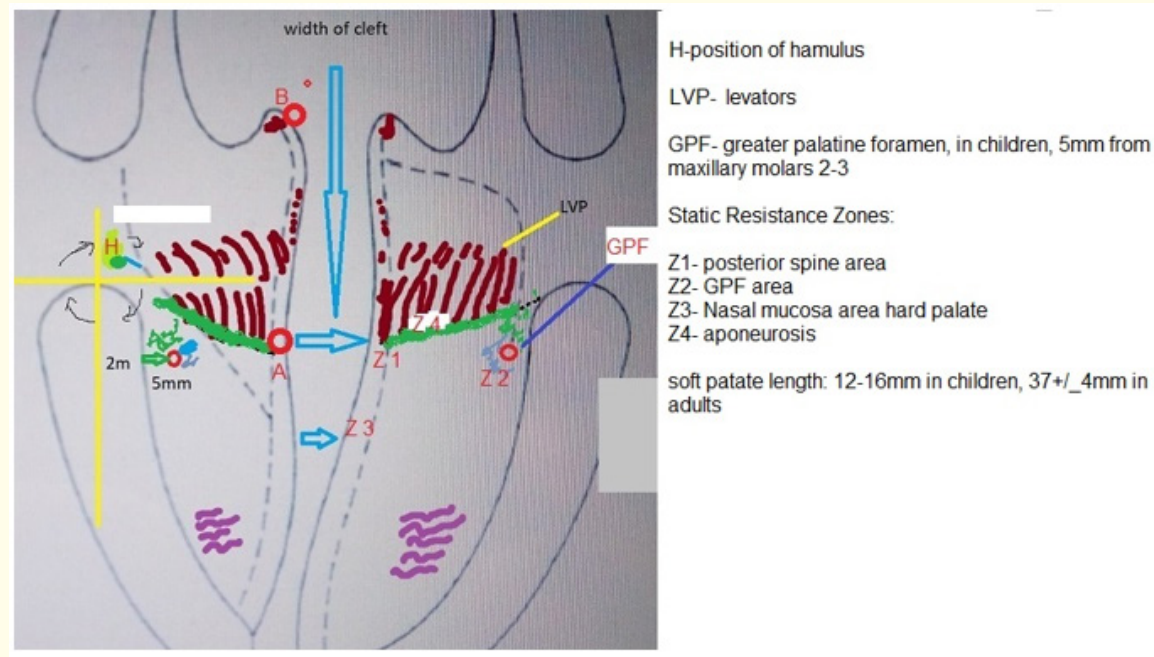

Figure 17: Areas of "static resistance" in cleft palate surgery, due to tight tissue planes. 


\section{Results and Observations}

The procedures using hydro dissection, cause minimal bleeding, and operating time is shortened significantly in Veau 1 and smaller Veau 2 cleft palates. There was no incidence of post-operative bleed, hypoxemia, or airway obstructive problems. The tongue remained normal both intraoperatively and postoperatively without any swelling or edema since the operating time was much less. The levator muscles were retro positioned for about 7 to 10 millimeters. The uvula was also 60 to 70 percent retro positioned by leaving more tissue posteriorly. 40 vicryl sutures were used for a watertight closure in all cases. No post-operative complications were encountered using this technique.

In two-stage palatoplasty, the first stage makes the second closure easier because of the narrowed palate. Although two flaps can be used for closure, we also find that the hemi palate hinge flap works well. In adults and older children, due to troublesome bleeding, the two-stage procedure becomes a useful addition especially in regions with less than adequate facilities. If an experienced pediatric anesthetist is available and medical infrastructure adequate, the one-stage palatoplasty can be done without any problems. Identifying the zones of static resistance enabled us to perform better repairs.

The main advantages were ease of closure without tension on the flaps, short operating time, less anesthesia time, and minimal blood loss.

\section{Discussion and Conclusion}

Blood loss in palatoplasty can be minimal, especially in Veau 1, 2 cleft palate if minimal incisions are used. The two-stage palate repair can also be used to reduce blood loss, in most cases. However, the Gothenburg protocol is not followed by all surgeons.

Minimal palatoplasty is relatively easy to perform for cleft trainees and leads to tension-free closure with very little blood loss Fistula and velopharyngeal insufficiency rates are comparable to that of other techniques, and theoretical advantages of this technique will be borne out by longer-term follow-up [15]. Cleft palate repair can cause problems postoperatively because of prolonged surgery. Tongue edema is known to occur due to prolonged pressure from the tongue blade. Some have suggested lessening this complication by the intermittent release of the blade, every 20 minutes [16]. Using a minimal incision technique lessens the operating time and we have not encountered any complications with this technique.
Scarring is minimal using button-hole or mini incisions for cleft palate repair. Levator retro positioning is the most important step of speech surgery since the muscle forms $50 \%$ of the bulk of mobile soft palate below the upper, static $25 \%$, close to the hard palate. Cutting has mentioned that veloplasty plays a significant role in speech after surgery [17].

Some groups have suggested that larger clefts may present with more maxillary retrusion later. This may be one reason to perform two-stage palatoplasty in children with the wide cleft palate. Liao., et al. noted that by the age of nine, patients who have larger clefts have more retrusion of the maxilla than children with smaller clefts [18].

Identifying key areas in palatoplasty helps the cleft surgeon to perform the surgeries with ease and avoid intraoperative complications as well as reduce blood loss. Some of the key areas we have mentioned above include the position of hamulus, greater palatine foramen, the area around the posterior spine, medial edge of the hard palate, mid rugae of the palate, the palatal aponeurosis and the sagittal inclination of the levators in cleft palate. Palatal ostectomy, known as the Limberg partial ostectomy of 1927, is an optional extra, sometimes quite useful in medializing the neurovascular bundle in a wide cleft. Mulliken demonstrated the technique to our craniofacial author, where he used a guarded osteotome to push the bundle laterally and enlarged the foramen in a posteromedial direction. This increases flap mobility significantly and also decreases tension on the flaps. This maneuver does not affect growth because most of the growth is posterior to the tuberosity after the age of three [19].

There is a lot of interest in the position of the greater palatine foramen (GPF), especially among dentists and cleft surgeons. The nerve lies medial to the artery and innervates the soft and hard tissues of the hard palate. In adults, the foramen is approximately $12 \mathrm{~mm}$ (about $5-6 \mathrm{~mm}$ in children) from to the plane over the alveolar crest of maxillary molars; it is behind the $2^{\text {nd }}$ molar in over 83 percent of cases [20].

Many controversies surround cleft palate repair, and surgeons have advocated different types of repairs. Our simple approach, for the benefit of younger cleft palate trainees, is to enable them to have a reasonable starting-point for the first few cases before they handle the more difficult problems associated with cleft palate surgery. We have found adrenaline saline hydro dissection a useful 
Rules of Engagement in Minimal Blood Loss Palatoplasty Using Saline Hydro Dissection: A Useful Learning Curve for Younger Cleft Surgeons in Manoeuvring Areas of Static Resistance due to Tight Tissue Planes

addition to palatoplasty procedures and would like to encourage younger cleft surgeons to use the technique.

In conclusion, although we are not able to cover many aspects of palatal surgery here, we hope that this paper will help our younger cleft surgeons to gain some experience in the art of cleft palate surgery.

\section{Bibliography}

1. Minimal blood loss palatoplasty Lotha B Yemen, $5^{\text {th }}$ European Plastic Surgery Research Council (2013).

2. Kinsella., et al. "Intraoperative High-Dose Epinephrine Infiltration in Cleft Palate Repair". The Journal of Craniofacial Surgery 25.1-3 (2014): 140-142.

3. Palate Brian C., et al. "International Confederation for Cleft Lip and Palate and Related Craniofacial Anomalies Task Force Report: Palatoplasty in the Speaking Individual with Unrepaired Cleft". The Cleft Palate-Craniofacial Journal 51.6 (2014): e122e128.

4. Mats E., et al. "Risk factors in children having palatoplasty". Indian Journal of Plastic Surgery 35 (2001): 279-283.

5. "Cleft Palate Repair". Clinics in Plastic Surgery 41 (2014): 189210

6. Lotha B., et al. "Intraoperative Anatomical Surface Marking and Cone Beam Computerized Tomography for Assessment of the Hamulus in Palatoplasty by Younger Cleft Surgeons". Acta Scientific Dental Sciences 4.7 (2020): 150-153.

7. Lohmander., et al. "Long-Term, Longitudinal Follow-Up of Individuals With Unilateral Cleft Lip and Palate After the Gothenburg Primary Early Veloplasty and Delayed Hard Palate Closure Protocol: Speech Outcome, Anette". The Cleft PalateCraniofacial Journal 49.6 (2012): 657-671.

8. M Eriguchi., et al. "Growth of unilateral cleft lip and palate patients undergoing two-stage palatoplasty and orthodontic treatment". Bull Tokyo Dental College 59.3 (2018): 183-191.

9. Rod J Rohrich MD., et al. "Optimal Timing of Cleft Palate Closure". Plastic And Reconstructive Surgery 106.2 (2000): 414421.

10. Don Larossa MD. "The State of the Art in Cleft Palate Surgery". Cleft Palate-Craniofacial Journal 37.3 (2000): 225-228.

11. Orgun Derrn. "Furlow palatoplasty in children". APRS 116 (2005): 1.

12. Patricio Andrades., et al. "The Importance of Radical Intravelar Veloplasty during Two-Flap Palatoplasty". Plastic and Reconstructive Surgery 122 (2008): 1121.
13. John H Grant. "Addition of radical intravelar palatoplasty significantly improves speech outcomes and reduces reoperation rate in primary palatoplasty". ACPA $69^{\text {th }}$ Annual conf, San Jose (2012): 112.

14. Brian Sommerlad. "A protocol in the management of VPI". ACPA $69^{\text {th }}$ Annual Conference (2012): 67.

15. Brian S Pan MD. "Evolution in Minimal-Incision Palatoplasty: Surgical Technique and Outcomes in 67 Consecutive Cases". Plastic and Reconstructive Surgery 134 (2014): 102.

16. Kulkarni KR., et al. "Perioperative respiratory complications in cleft lip and palate repairs: An audit of 1000 cases under the 'Smile Train Project". Indian Journal of Anaesthesia 57.6 (2013): 562-568.

17. Cutting MD., et al. "The technique of muscle repair in the cleft palate". Operative Techniques in Plastic and Reconstructive Surgery 2.4 (1995): 215-222.

18. YF Liao., et al. "Cleft size at the time of palate repair in complete unilateral cleft lip and palate as an indicator of maxillary growth". International Journal of Oral and Maxillofacial Surgery 39 (2010): 956-961.

19. Albert Oh MD., et al. "An Osteotome for Out fracture of the Greater Palatine Foramen in Cleft Palate Repair". Plastic and Reconstructive Surgery 107.3 (2001): 820-822.

20. M Beetle., et al. "A micro-CT study of the greater palatine foramen in human skulls". Journal of Oral Science 60.1 (2018): 51-56.

\section{Assets from publication with us}

- Prompt Acknowledgement after receiving the article

- Thorough Double blinded peer review

- Rapid Publication

- Issue of Publication Certificate

- High visibility of your Published work

Website: $\underline{w w w}$.actascientific.com/

Submit Article: www.actascientific.com/submission.php

Email us: editor@actascientific.com

Contact us: +919182824667

Citation: Bona Lotha and Zeinalddin M. "Rules of Engagement in Minimal Blood Loss Palatoplasty Using Saline Hydro Dissection: A Useful Learning Curve for Younger Cleft Surgeons in Manoeuvring Areas of Static Resistance due to Tight Tissue Planes”. Acta Scientific Medical Sciences 4.11 (2020): $36-42$. 